\title{
Spatio-temporal distribution of eosinophils in the mouse uterus during peri-implantation period
}

\author{
By \\ Tomomi Kurane ${ }^{1, ~ *, ~ F u m i e ~ K a w a s e ~}{ }^{2, ~ *, ~ A k i r a ~ M o r o o k a ~}{ }^{3}$, Toshihiro Konno ${ }^{1,2}$ \\ ${ }^{1}$ Molecular Microbiology Group, Tropical Biosphere Research Center and Department of Host Defense, \\ Graduate School of Medicine, University of the Ryukyus, Senbaru 1, Nishihara, Okinawa 903-0213, Japan \\ ${ }^{2}$ The United Graduate School of Agricultural Sciences, Kagoshima University, 1-21-24 Korimoto, Kagoshima 890-0065, Japan \\ ${ }^{3}$ Department of Subtropical Agro-Environmental Sciences, Faculty of Agriculture, University of the Ryukyus, \\ Senbaru 1, Nishihara, Okinawa 903-0213, Japan
}

-Received for Publication, April 8, 2019-

Key Words: eosinophils, estrogen, estrogen receptor, endometrium, embryo implantation

\begin{abstract}
Summary: Embryo implantation is an immunologically paradoxical event. In humans and rodents, blastocysts adhere to uterine epithelium and then invade into endometrial stroma, while maternal body is protected from extraneous materials by its immune system. Eosinophils, a kind of leucocytes involving parasitic infections and allergic response, increase in number in uterus when serum estrogen level is elevated during estrus cycles. However, response of uterine eosinophils to ovarian estrogen during peri-implantation period is not clear. Therefore, we investigated the distribution of eosinophils in murine peri-implantation uterus. On day 0.5 of pregnancy, eosinophils were found primarily in endometrial stroma near the luminal epithelium, whereas they were primarily distributed in basal endometrium and myometrium on day 3.5 of pregnancy. The number of uterine eosinophils on day 4.5 of pregnancy was significantly increased by inhibition of maternal estrogen action. Collectively, our results indicate that the ovarian estrogen negatively regulates uterine eosinophil distribution during peri-implantation period and provide insight into a role of maternal immune system in embryo implantation.
\end{abstract}

\section{Introduction}

The fetus represents a foreign entity to the maternal immune system, as it expresses genes of both paternal and maternal origins. Therefore, the immune tolerance toward fetal antigens is essential for successful pregnan$\mathrm{cy}^{1}$. While adaptive immunity against fetus and placenta is suppressed during pregnancy, innate immune cells recruited to the fetal-maternal interface, such as uterine natural killer cells and antigen presenting cells including dendritic cells and macrophages, are known to play a role in modulating vascular remodeling and trophoblast inva$\operatorname{sion}^{2-5)}$.

Eosinophils are cells of the innate immune system that are abundantly found in the mucosal tissues of the gastrointestinal, respiratory and urogenital tracts and also prominent in host responses to parasitic worm and viral infections and in allergic diseases ${ }^{6}$. Eosinophils differentiate from myeloid precursor cells during hematopoiesis in the bone marrow. Interleukin-5 (IL-5) is known to be a major cytokine responsible for development of eosinophils in the bone marrow ${ }^{7)}$. After maturation, eosinophils circulate in blood and migrate to their destination tissues in response to chemokines, such as eotaxin-1 (also known as CCL11) and eotaxin-2 (also known as CCL24) via eotaxin receptor $\mathrm{CCR} 3^{8}$. Effector functions of the eosinophils are attributed to their secretion of various cytokines and cationic proteins and implicated in various biological processes, such as host defense, organ formation, and tissue repair6).

Uterine endometrium has been recognized as a tissue with abundant distribution of eosinophils. In rodents, uterine distribution of eosinophils fluctuates with the estrus cycle, with the numbers reaching a maximum at estrus and metestrus ${ }^{9}$. Also, studies in humans and mice have shown that eosinophils accumulate in the uterus in association with the cervix preparation for delivery and the uterine tissue regeneration after parturition ${ }^{10-13}$.

\footnotetext{
* T.K. and F.K. contributed equally to this work.

Corresponding author: Toshihiro Konno, Ph.D. Department of Subtropical Agro-Environmental Sciences, Faculty of Agriculture, University of the Ryukyus, Senbaru 1, Nishihara, Okinawa 903-0213, Japan. E-mail: konnot@agr.u-ryukyu.ac.jp
} 
However, mice deficient in IL-5 or genetically lacking eosinophils are fertile and exhibit normal parturition ${ }^{14-16)}$. Thus, specific roles for uterine eosinophils in the steadystate and in the pregnancy remain unclear.

In rodents, eosinophil recruitment to the cycling uterus have been comprehensively studied. Eosinophil infiltration of the uterus is induced by estrogen-driven endometrial expression of eotaxin- $1^{16}$. Uterine eosinophils are increased in number and localized primarily in the subepithelial zone of endometrial stroma upon exposure to seminal fluid at mating, and then diminish over subsequent days ${ }^{10,12)}$. However, the effect of nidatory estrogen on uterine eosinophil distribution still remains unclear. Therefore, in this study, we investigated spatiotemporal distribution of eosinophils in peri-implantation uterus utilizing estrogen receptor inhibition mice model.

\section{Material and method}

\section{Animals and tissue preparation}

ICR mice (Japan SLC, Shizuoka, Japan) were housed in an environmentally controlled facility and allowed free access to food and water. Timed matings of mice were carried out by placing females ( $>8$ weeks of age) with fertile or vasectomized males. The day when a seminal plug was found was defined as 0.5 days post coitum (dpc). Pregnant or pseudopregnant uteri were collected on $0.5,3.5,4.5,5.5$ and $7.5 \mathrm{dpc}$, and snap-frozen in dry ice-cooled heptane for histological analyses. This study was approved by the Committees on Ethics in Animal Experiments in the University of the Ryukyus. Experiments were carried out under the control of the Guideline for Animal Experiments of the University of the Ryukyus.

\section{Estrogen receptor inhibition model}

To evaluate the effect of nidatory estrogen on uterine eosinophil distribution, mice were administrated intraperitoneally with either ICI 182,780 ( $0.5 \mathrm{mg} /$ mouse), a small molecule estrogen receptor antagonist, or vehicle on 2.5 $\mathrm{dpc}$, then the uterine tissues were collected on day $4.5 \mathrm{dpc}$ and subjected for histological analyses and flow cytometry.

\section{Histological analyses}

Histological analyses were performed on $10 \mu \mathrm{m}$ fresh frozen sections of uterine tissues prepared with the aid of a cryostat. To identify eosinophils, we utilized the phenol red method, which is previously described as a simple and rapid method for identifying eosinophils in rat uterus ${ }^{17}$. Briefly, the frozen sections of uterine tissues were fixed with $4 \%$ paraformaldehyde (PFA) in phosphate-buffered saline (PBS), and then incubated with Hank's balanced salt solution (HBSS) containing phenol red (14170-120; Thermo Fisher Scientific, Waltham, MA, USA) for $2 \mathrm{~h}$. The tissue sections were then nuclearstained with 4',6- diamidino-2-phenylindole (DAPI) and observed under fluorescence microscopes (Leica DMI4000B and Leica M205FA, Leica Microsystems GmbH, Wetzlar, Germany).

To visualize endogenous peroxidase activity, tissue sections were briefly fixed with 4\%PFA in PBS and then incubated with 3-Amino-9-Ethylcarbazole (AEC) substrate solution (001122, Thermo Fisher Scientific). Mayer's hematoxylin was used for counterstaining.

Immunohistochemistry using rat anti-Neutrophil monoclonal antibody (1:5000 dilution; ab2557; Abcam, Cambridge, UK) was performed to detect neutrophils. Anti-rat IgG biotin conjugate antibody (1:800 dilution; B7139; Sigma-Aldrich, St. Louis, MO, USA) was used for secondary antibody. Immunolocalization was visualized using ExtrAvidin-peroxidase (E2886, Sigma-Aldrich) and AEC substrate solution. AEC stained sections were counterstained with Mayer's hematoxylin.

To distinguish myometrium from endometrial stroma, immunofluorescence was performed on uterine tissue sections using Alexa-fluor 488 conjugated rabbit antialpha-smooth muscle actin monoclonal antibody (1:100 dilution; 34105, Cell Signaling Technology, Danvers, MA, USA).

Morphometric image analysis to measure eosinophil density

Images of uterine tissue sections that were processed to detect eosinophils by the phenol red method were captured at 120x magnification using a Leica M205FA fluorescence stereomicroscope (Leica Microsystems $\mathrm{GmbH})$. Fluorescently labeled eosinophils were counted in six square areas (300 pixels $\times 300$ pixels, equivalent to $134.75 \mu \mathrm{m} \times 134.75 \mu \mathrm{m})$ selected randomly from endometrial-myometrial junction zone. Eosinophil density in uterine endometrial-myometrial junction zone (number of eosinophils $/ \mathrm{mm}^{2}$ ) was determined by calculating average eosinophil counts of six areas. Image analysis was performed using FIJI ${ }^{18,19}$ ). Uterine tissues from four individuals per experimental group were subjected for the analysis.

\section{Flow cytometry}

Single cell suspension was prepared from the ureri as follows: the uteri were minced in PBS using a GentleMACS dissociator (Miltenyi Biotec, Bergisch Gladbach, Germany), and treated with collagenase type I (12,500 U/ $\mathrm{ml})$, DNase I (600 U/ml) and hyaluronidase type IV (6000 $\mathrm{U} / \mathrm{ml}$ ) for 30 minutes at $37^{\circ} \mathrm{C}$. The tissue fragments were passed through a stainless steel mesh to obtain a single cell suspension. The cells were suspended in $45 \%$ Percoll and centrifuged at $2000 \mathrm{rpm}$ for 20 minutes. The pellet was collected, and red blood cells were lysed to obtain white blood cells. Before staining with $\mathrm{mAb}$ to detect eosinophils, the uterine white blood cells were pretreated with ant-mouse CD16/32 mAb (Fc-block) to block non-specific binding of antibodies to Fc $\gamma$ receptors. The 
cells were then stained with FITC-conjugated anti-mouse Ly-6G/Ly-6C (Gr-1) (553127, BD Biosciences, San Jose, CA, USA), and biotin-conjugated anti-mouse CD45 (103103, BioLegend, San Diego, CA, USA) mAb, followed by PE/Dazzle-conjugated streptavidin (405247, BioLegend). To stain both cell surface and intracellular CCR3, the cells were fixed and permeabilized with Fixation/Permeabilization Solution Kit (554714, BD Biosciences), followed by Alexa Flour 647-conjugated anti-mouse CCR3 (129401, BioLegend), The stained cells were analyzed with a FACSCanto flow cytometer with DIVA software (BD Biosciences). Eosinophils were detected as CD45+ Ly-6G/Ly6C- CCR3+ cells. Uterine samples from five individuals per experimental group were subjected for the analysis.

\section{Statistics}

The mean eosinophil density measurements between uteri from experimental mice groups were compared by analyses of variance followed by Tukey's contrast tests. The mean numbers of uterine eosinophils between two experimental mice groups were compared by Student's T Tests. All statistical analysis was performed using R statistical packages (http://www.r-progect.org).

\section{Results}

\section{Identification of uterine eosinophils}

The phenol red method was previously described as a convenient technique for identification of eosinophils in rat uterus ${ }^{17)}$. Therefore, we first evaluated whether the phenol red method is applicable for detection of uterine eosinophils in mice. In $3.5 \mathrm{dpc}$ uterus, fluorescently labeled cells by the phenol red method were primarily populated in the basal endometrium and myometrium (Fig. 1A-C). Peroxidase positive cells exhibited similar distribution to the cells detected by the phenol red method (Fig. 1D). Eosinophils produce and store their specific peroxidase in the cytoplasmic granules, which is one of the characteristics of eosinophils ${ }^{20)}$. Another characteristic of eosinophils is their multilobed nucleus ${ }^{20)}$. Observation of phenol red labeled cells revealed that these cells possessed multilobed nucleus (Fig. 1E). The nuclei of peroxidase positive cells also exhibited multilobed shape (Fig. 1F). Neutrophils are another cell type that possesses peroxidase-containing granules. Since neutrophils are known to migrate into the uterus after insemination and rapidly declines on 1.5 and $2.5 \mathrm{dpc}^{21)}$, we next performed a combined staining with phenol red and anti-neutrophil antibody on $0.5 \mathrm{dpc}$ uterine tissue sections (Fig. 1G and $\mathrm{H})$. Neutrophils as they were detected by anti-neutrophil antibody (Fig. 1H) were not labeled by the phenol red method (Fig. 1G). We also evaluated the specificity of phenol red method on peripheral blood smears. DiffQuick stain clearly distinguished eosinophils and neutro- phils in peripheral blood smears (Fig. 2A and B). Phenol red/anti-neutrophil dual staining on peripheral blood smears indicated that phenol red stains eosinophils (Fig. 2C), but not neutrophils (Fig. 2D). These results indicated that the phenol red method is applicable for detection of uterine eosinophils in mice.

\section{Dynamics of eosinophil distribution in early pregnancy uterus}

We next investigated the uterine eosinophil distribution during early pregnancy by utilizing the phenol red method. On $0.5 \mathrm{dpc}$, eosinophils were primarily distributed in the subepithelial zone of the endometrial stroma, while they were sparsely populated the basal endometrium and myometrium (Fig. 3A and F). Eosinophil distribution in $3.5 \mathrm{dpc}$ uterus was opposite from that observed in $0.5 \mathrm{dpc}$ uterus, as they were primarily distributed in the basal endometrium and myometrium and sparsely populated in the subepithelial stroma (Fig. 3B and G). On 4.5 $\mathrm{dpc}$, eosinophils were localized in the basal endometrium and myometrium and rarely seen in the subepithelial endometrium (Fig. 3C and H). On 5.5 and $7.5 \mathrm{dpc}$, eosinophils were found in the myometrium while they were hardly detected in decidua (Fig. 3D, E, I and J).

In rodents, uterine endometrial stromal cells proliferate and differentiate to form decidua upon embryo implantation into uterine endometrium. Our results suggested that eosinophils rarely infiltrate into decidualized tissues (Fig. 3D, E, I and J). Since the decidualization does not occur in pseudopregnancy ${ }^{22}$, we next evaluated uterine eosinophil distribution in pseudopregnancy. On $5.5 \mathrm{dpc}$ of pseudopregnancy, eosinophils were primarily localized in the basal endometrium and myometrium (Fig. 4A and C). In $7.5 \mathrm{dpc}$ pseudopregnant uterus, eosinophils were distributed to the basal endometrium and myometrium, and their sparse distribution was also found in the subepithelial endometrium (Fig. 4B and D).

\section{Effect of nidatory estrogen on uterine eosinophil distribu- tion}

In mice, embryo implantation into uterine endometrium is confined to a specific interval during gestation referred to as the "window of embryo implantation receptivity"23). The uterine receptivity for embryo implantation is promoted by ovarian estrogen which reaches a maximum serum level on $4.0 \mathrm{dpc}$ (midnight of $3.5 \mathrm{dpc}$ ) and rapidly declines afterwards ${ }^{24)}$. To evaluate the influence of nidatory estrogen on uterine eosinophil distribution, we examined $4.5 \mathrm{dpc}$ uterine tissues from mice administered with ICI 182,780, a small molecule antagonist specific for estrogen receptor $\alpha$, on $2.5 \mathrm{dpc}$. In the vehicle administrated mice, uterine eosinophils were primarily localized in the basal endometrium and myometrium and sparsely distributed in the subepithelial endometrium (Fig. 5A and C). ICI 182,780 administration did not affect to their distribution (Fig. 5B and D). Although the inhibition of 

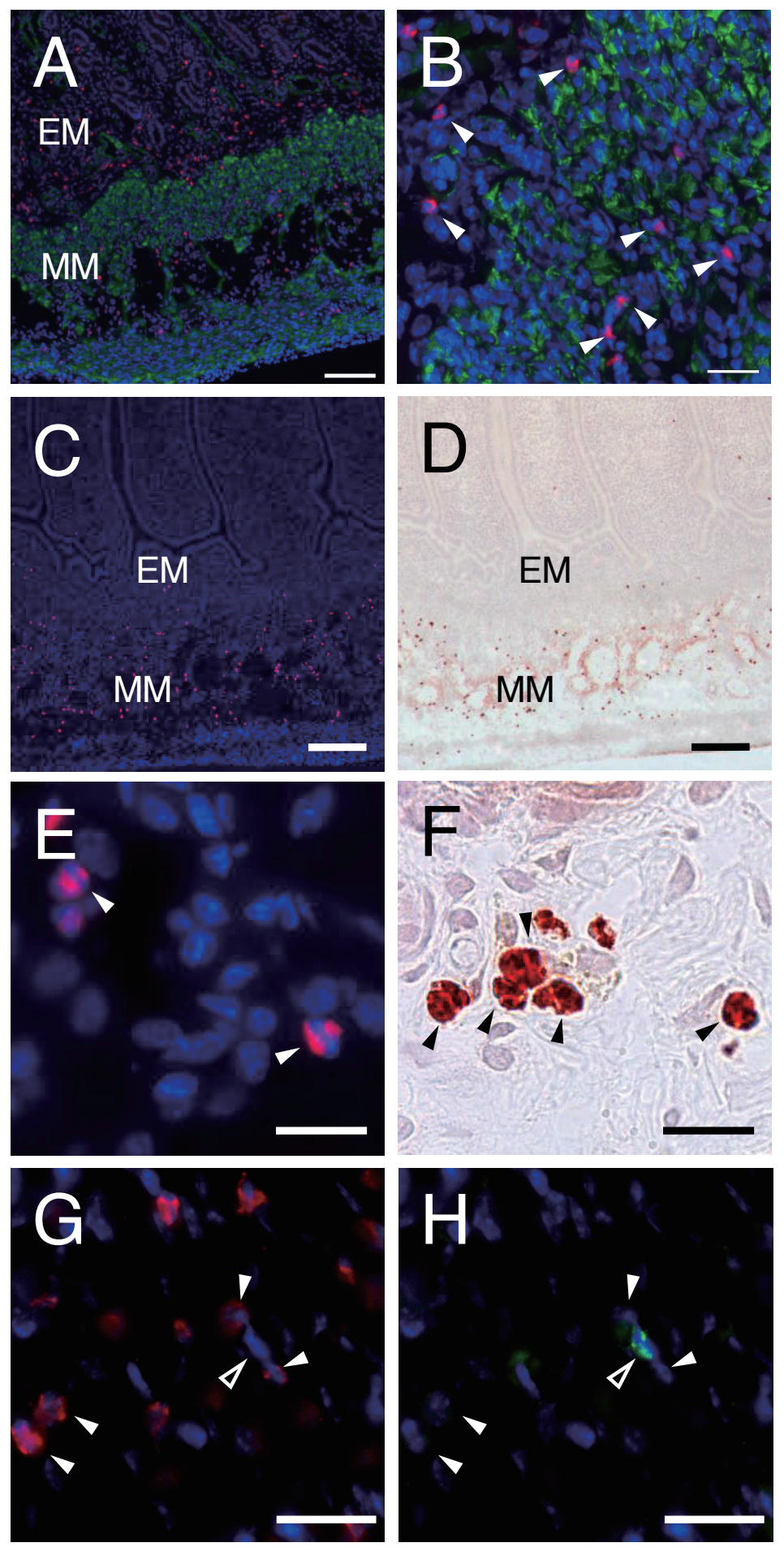

Fig. 1. Identification of eosinophils in mouse uterus. (A) $3.5 \mathrm{dpc}$ uterine sections were analyzed by the phenol red method (red) and immunofluorescence for $\alpha$-smooth muscle actin (green). Nuclearstain: DAPI. Bar $=100 \mu \mathrm{m}$. EM: endometrium; MM: myometrium. (B) Higher magnification image of A highlighting endothelial-myometrial junction. Bar $=25 \mu \mathrm{m}$. White arrowheads: eosinophils. (C) Analysis of 3.5 dpc uterus by the phenol red method. Nuclearstain: DAPI. Bar $=200 \mu \mathrm{m}$. EM: endometrium; MM: myometrium. (D) Peroxidase activity analysis of $3.5 \mathrm{dpc}$ uterus. Peroxidase positive cells were visualized by AEC chromogen (red). Uterine sections were counterstained with Mayer's hematoxylin. Bar $=200 \mu \mathrm{m}$. Note that peroxidase positive cells distributed similarly to the cells detected by the phenol red method. (E and F) High magnification images of the phenol red analysis (E) and the peroxidase activity analysis (F). Both phenol red labeled cells (white arrowheads) and peroxidase positive cells (black allowheads) possessed multilobed nuclei. bars $=20 \mu \mathrm{m}$. (G and $\mathrm{H})$ Phenol red method $(\mathrm{G})$ and immunofluorescence for neutrophil $(\mathrm{H})$ were performed the same tissue sections of $0.5 \mathrm{dpc}$ uterus. Bars $=20 \mu \mathrm{m}$. White arrowheads: phenol red labeled cells; Open arrowheads: neutrophils as detected by anti-neutrophil antibody. 

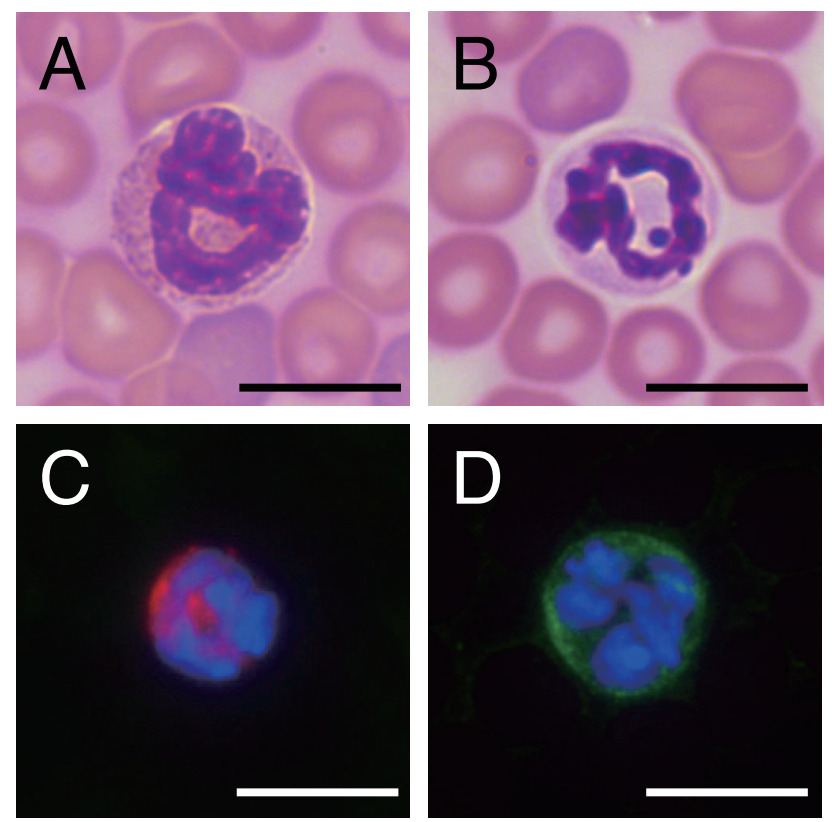

Fig. 2. Validation of phenol red method on peripheral blood smears. (A and B) peripheral blood smears from $4.5 \mathrm{dpc}$ mice were processed for Diff-Quick stain. (A) Eosinophil. (B) Nuetrophil. Bars $=10 \mu \mathrm{m}(\mathrm{C}$ and D) Dual staining with phenol red (red) and anti-neutrophil antibody (green) was performed on the peripheral blood smears. The phenol red-labeled cells were negative for anti-neutrophil antibody (C), while neutrophils as detected by anti-neutrophil antibody were not labeled with phenol red (D). Bars $=10 \mu \mathrm{m}$.

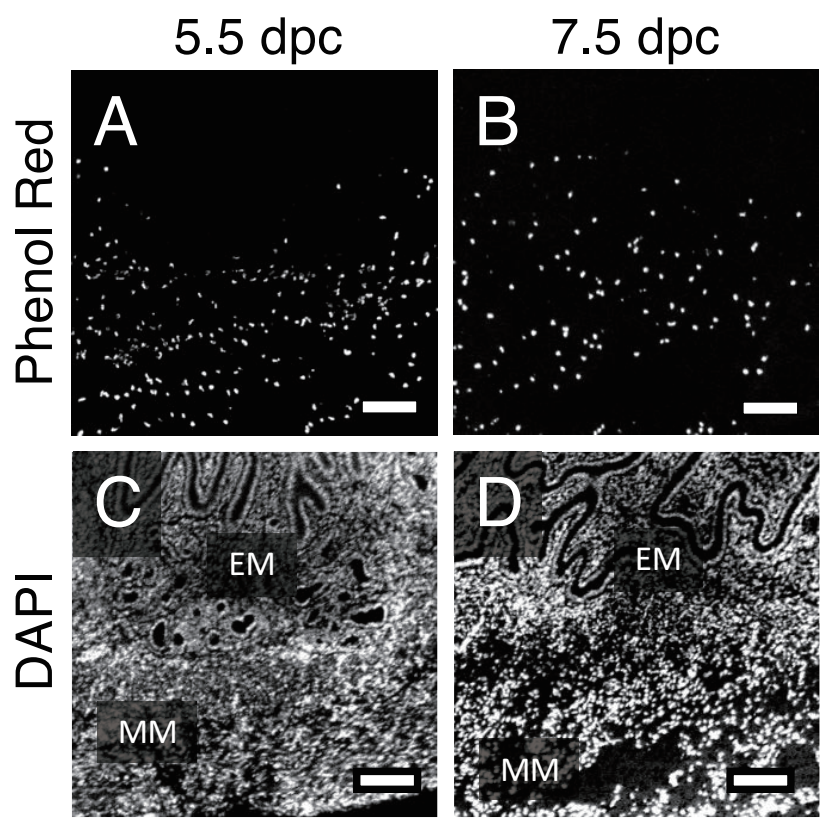

Fig. 4. Eosinophil distribution in pseudopregnant uterus. Tissue sections of 5.5 and $7.5 \mathrm{dpc}$ pseudoprennant uteri were analyzed by the phenol red method (A and B) and nuclearstained with DAPI $(\mathrm{C}$ and $\mathrm{D})$. Bars $=100 \mu \mathrm{m}$. EM: endometrium; MM: myometrium.
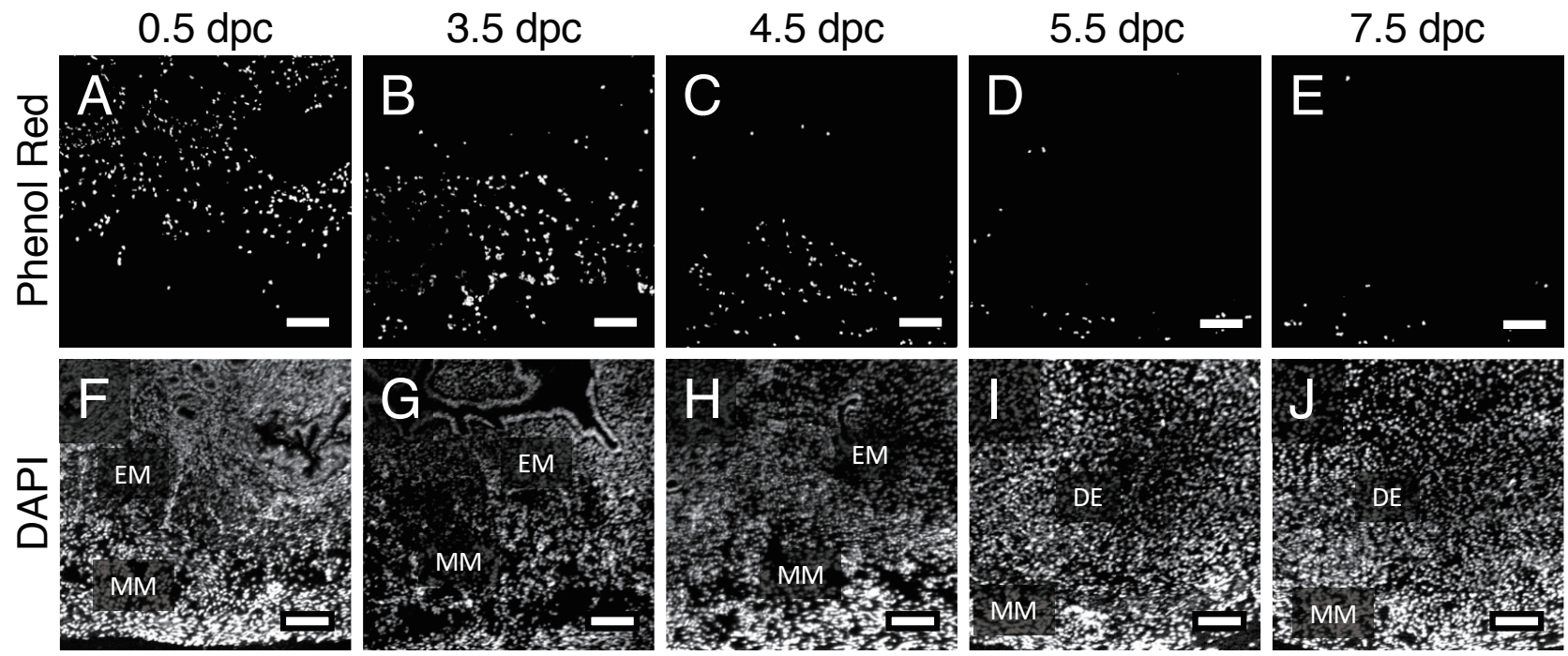

Fig. 3. Spatio-temporal distribution of uterine eosinophils. Uterine tissue sections from 0.5 (A and F), 3.5 (B and G), 4.5 (C and H), 5.5 (D and I) and $7.5 \mathrm{dpc}(\mathrm{E}$ and $\mathrm{J})$ mice were analyzed by the phenol red method (A-E) and nuclearstained with DAPI (F-J). Bars $=100 \mu \mathrm{m}$. EM: endometrium; MM: myometrium; DE; decidua. 

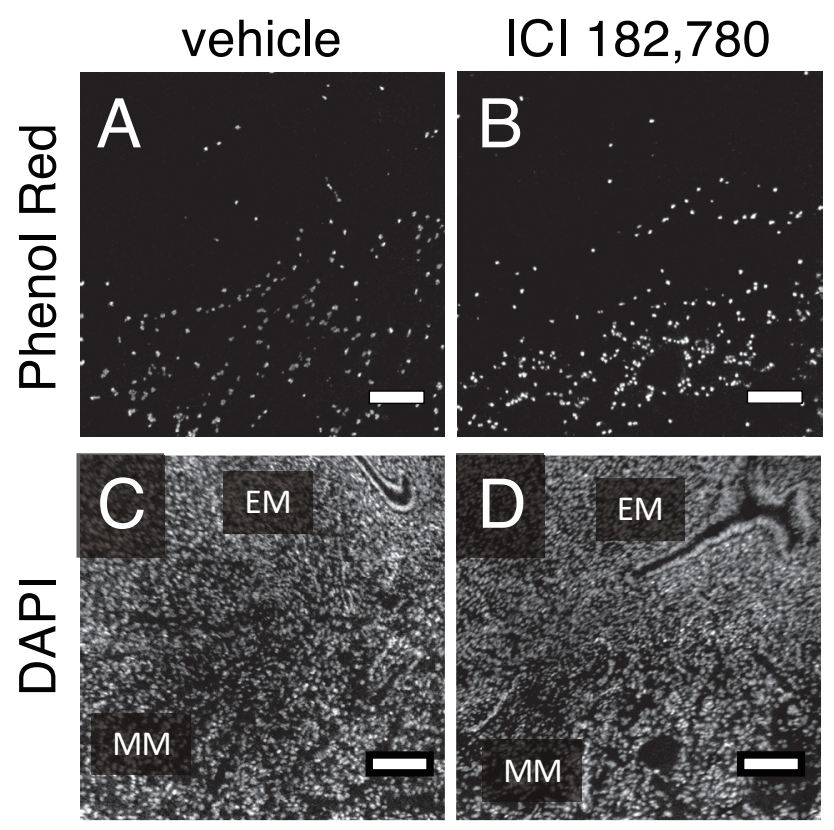

Fig. 5. Effect of estrogen receptor $\alpha$ inhibition on uterine eosinophil distribution. $4.5 \mathrm{dpc}$ uteri form mice administrated with either vehicle (A and C) or ICI 182,780 (B and D) were analyzed by the phenol red method (A and B) and nuclearstained with DAPI (C and D). Bars $=100 \mu \mathrm{m}$. EM: endometrium; MM: myometrium.

estrogen receptor $\alpha$ did not alter the localization of uterine eosinophils, the eosinophil density in $4.5 \mathrm{dpc}$ uterus was significantly increased by the ICI 182,780 administration (Fig. 6A). The flow cytometry analysis of $4.5 \mathrm{dpc}$ uteri also indicated that eosinophils were increased in number by the inhibition of estrogen receptor $\alpha$ (Fig. 6B).

\section{Discussion}

Our observations indicated that eosinophils were distributed primarily in the subepithelial zone of endometrium on $0.5 \mathrm{dpc}$, and then their localization was shifted to the basal endometrium and myometrium over subsequent days. These results were consistent with previous studies $^{10,12)}$. We also demonstrated that the inhibition of estrogen receptor $\alpha$ increased the number of eosinophils in $4.5 \mathrm{dpc}$ uterus. This observation suggests suppressive effect of estrogen on eosinophil accumulation in periimplantation uterus, while estrogen is known to promote tissue infiltration of eosinophil in normal cycling uterus.

Estrogen is a steroid hormone essential for normal development of female sexual characteristics, which exerts effect in the endometrium via two nuclear estrogen receptor isoforms, estrogen receptor $\alpha$ and $\beta^{25)}$. Estrogen receptor $\alpha$ is a major receptor responsible for the main function of the endometrium, embryo implantation.
A

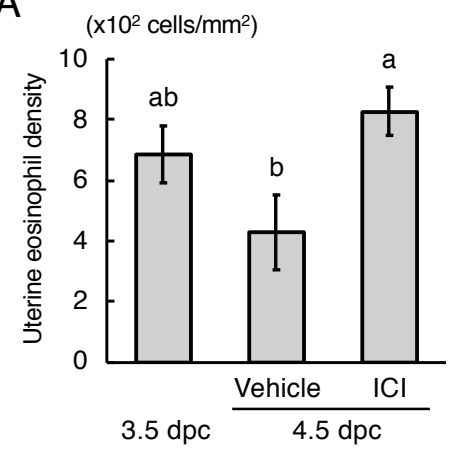

B

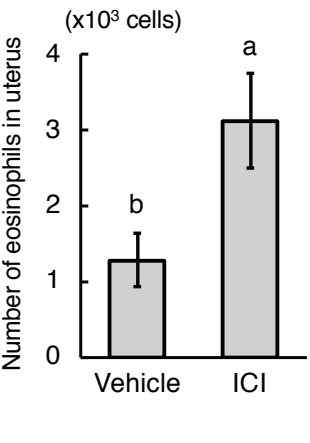

Fig. 6. Effect of estrogen receptor $\alpha$ inhibition on uterine eosinophil densities and numbers. (A) Comparison of uterine eosinophil densities between $3.5 \mathrm{dpc}$ intact mice and $4.5 \mathrm{dpc}$ mice treated with either vehicle or ICI 182,780 (ICI). Error bars: standard error of means; $\mathrm{n}=4$ for each group. $\mathrm{a}>\mathrm{b}(P<0.05)$. (B) Comparison of eosinophil numbers in $4.5 \mathrm{dpc}$ uterus between vehicle treated and ICI 182,780 (ICI) treated mice. Error bars: standard error of means; $\mathrm{n}=5$ for each group. $\mathrm{a}>\mathrm{b}(P<0.05)$.

Previous study demonstrated that female mice with null mutation in the gene for estrogen receptor $\alpha$ are infertile and exhibit infantile phenotype, while mice lacking estrogen receptor $\beta$ are fertile 26,27$)$.

Activation of estrogen receptors is also essential for uterine infiltration of eosinophils in the pubertal and cycling uterus ${ }^{16)}$. Previous study has demonstrated that treatment of immature rats with estradiol increases uterine eosinophil chemotaxis, and the estradiol-stimulated chemotaxis is estrogen receptor dependent ${ }^{28)}$. Eotaxins are a subfamily of chemokines that specifically target eosinophils. There are three eotaxins, eotaxin-1, eotaxin-2 and eotaxin-3 (also known as CCL26), and eotaxin-1 is responsible for uterine eosinophil infiltration ${ }^{6,8)}$. Previous study reported that injection of estradiol into ovariectomized or immature mice dramatically increased endometrial expression of eotaxin-1, and eosinophil infiltration into endometrium was not observed in mice lacking eotaxin- ${ }^{16}$. These observations indicate that the effect of estrogen on eosinophil infiltration into pubertal and cycling uterus is indirect and mediated through the estrogen-driven endometrial expression of eotaxin-1.

Estrogen may also have direct effect on eosinophils, at least in humans. Human eosinophils express G-proteincoupled estrogen receptor (GPER/GPR30), a membrane receptor for estrogen ${ }^{29}$ ). In vitro study of human eosinophil demonstrated that activation of GPER enhanced eotaxin-1-directed eosinophil chemotaxis although GRER activation alone did not induce eosinophil chemotaxis ${ }^{29}$. In our study, ICI 182,780 administration increased eosinophils in 4.5 dpc uterus. Since ICI 182,780 is a specific antagonist for estrogen receptor $\alpha$, the suppressive effect of estrogen on eosinophil accumulation in peri-implanta- 
tion uterus is probably independent of GPER.

Our results suggested that the suppressive effect of nidatory estrogen on uterine eosinophil distribution is mediated through the activation of estrogen receptor $\alpha$. However, the fate of the uterine eosinophils still remains to be elucidated. While estrogen receptor $\alpha$ is known to be expressed in hematopoietic stem cells and several immune cells ${ }^{30,31)}$, the expression in eosinophils has not yet been reported, and it is thus not clear whether ovarian estrogen or ICI 182,780 administration has direct effect on uterine eosinophils during peri-implantation period. On the other hand, the expression of estrogen receptor $\alpha$ in murine peri-implantation uterus has been studied in detail. Estrogen receptor $\alpha$ is primarily expressed in the luminal and glandular epithelia and is also expressed in the subepithelial stromal cells at low level ${ }^{32)}$. Therefore, the ovarian estrogen may alter the endometrial production of cytokines, which influence motility or survival of eosinophils.

The suppressive effect of estrogen on tissue eosinophil accumulation has also been described in inflammation of non-reproductive tissues. In murine model of airway hyper-responsiveness induced by ovalbumin, estrogen exhibits dual role in regulating eosinophils; estrogen treatment increases the number of eosinophils in lung in the process of antigen sensitization, whereas estrogen reduces levels of eosinophils present in lung during the effector phase of the response to inhaled antigen ${ }^{33)}$. Estradiol administration to acute peritoneal inflammation model mice also inhibits peritoneal eosinophil accumulation by impairing eosinophil mobilization and survival, and these effects of estradiol administration are mediated through estrogen receptor $\alpha^{34)}$.

In rodents, ovarian estrogen is a major regulatory factor for uterine receptivity ${ }^{23}$. During the "window of embryo implantation receptivity," the uterus is primed to produce a range of proinflammatory cytokines, including IL-6 and $\mathrm{TNF}^{35}$. These cytokines can be secreted by the endometrial cells as well as cells of the immune system recruited to the endometrium. This inflammatory reaction is essential for successful implantation and mediated through the combined effect of ovarian steroid hormones, progesterone and estrogen ${ }^{36,37}$. Our results demonstrated the inhibition of estrogen receptor $\alpha$ increased uterine eosinophil accumulation. The inhibition of estrogen receptor $\alpha$ also causes incomplete priming for uterine inflammation reaction. Therefore, inflammatory cytokines produced in estrogen-primed endometrium are probably involved in the reduction of uterine eosinophil accumulation during peri-implantation period.

In conclusion, we demonstrated for the first time that estrogen reduces uterine eosinophil accumulation through estrogen receptor $\alpha$. The effect of estrogen on eosinophil accumulation, which is promotive in pubertal and cycling uterus, may be altered by the inflammed status of endometrium during peri-implantation period. Further investigation into the regulatory mechanisms of uterine eosinophil may provide insights into the role for maternal immune system in embryo implantation.

\section{Acknowledgement}

Authors thank Drs. Goro Matsuzaki and Masayuki Umemura (University of the Ryukyus, Okinawa, Japan) for their assistance in analyzing results and their advice regarding flow cytometry technique. This study was supported by a Grant-in-Aid for Scientific Research (C) (15K07767) from the Japan Society for the Promotion of Science (JSPS) and University of the Ryukyus Research Project Promotion Grant (Strategic Research Grant) (18SP02101).

\section{References}

1) Trowsdale J, Betz AG: Mother's little helpers: mechanisms of maternal-fetal tolerance. Nat Immunol 2006; 7:241-246.

2) Chakraborty D, Rumi MAK, Konno T, Soares MJ: Natural killer cells direct hemochorial placentation by regulating hypoxiainducible factor dependent trophoblast lineage decisions. Proc Natl Acad Sci U S A 2011; 108:16295-16300.

3) Gonzalez MJ, Miranda-Massari JR, Berdiel MJ, Duconge J, Rodríguez-López JL, Hunninghake R, Cobas-Rosario VJ: High Dose Intraveneous Vitamin $\mathrm{C}$ and Chikungunya Fever: A Case Report. J Orthomol Med 2014; 29:154-156.

4) Hunt JS, Robertson SA: Uterine macrophages and environmental programming for pregnancy success. J Reprod Immunol 1996; 32:1-25.

5) Barrientos G, Tirado-González I, Klapp BF, Karimi K, Arck PC, Garcia MG, Blois SM: The impact of dendritic cells on angiogenic responses at the fetal-maternal interface. J Reprod Immunol 2009; 83:85-94.

6) Weller PF, Spencer LA: Functions of tissue-resident eosinophils. Nat Rev Immunol 2017; 17:746-760.

7) Palframan RT, Collins PD, Severs NJ, Rothery S, Williams TJ, Rankin SM: Mechanisms of acute eosinophil mobilization from the bone marrow stimulated by interleukin 5: the role of specific adhesion molecules and phosphatidylinositol 3-kinase. J Exp Med 1998; 188:1621-1632.

8) Jung Y, Rothenberg ME: Roles and regulation of gastrointestinal eosinophils in immunity and disease. J Immunol 2014; 193:9991005.

9) Ross R, Klebanoff SJ: The eosinophilic leukocyte. Fine structure studies of changes in the uterus during the estrous cycle. J Exp Med 1966; 124:653-660.

10) De M, Choudhuri R, Wood GW: Determination of the number and distribution of macrophages, lymphocytes, and granulocytes in the mouse uterus from mating through implantation. J Leukoc Biol 1991; 50:252-262.

11) Duchesne MJ, Badia E: Immunohistochemical localization of the eosinophil major basic protein in the uterus horn and cervix of the rat at term and after parturition. Cell Tissue Res 1992; 270:79-86.

12) Robertson SA, Mau VJ, Tremellen KP, Seamark RF: Role of high molecular weight seminal vesicle proteins in eliciting the uterine inflammatory response to semen in mice. J Reprod Fertil 1996; 107:265-277.

13) Knudsen UB, Uldbjerg N, Rechberger T, Fredens K: Eosinophils in human cervical ripening. Eur J Obstet Gynecol Reprod Biol 
1997; 72:165-8.

14) Kopf M, Brombacher F, Hodgkin PD, Ramsay AJ, Milbourne EA Dai WJ, Ovington KS, Behm CA, Köhler G, Young IG, Matthaei KI: IL-5-Deficient mice have a developmental defect in CD5+ B-1 cells and lack eosinophilia but have normal antibody and cytotoxic T cell responses. Immunity 1996; 4:15-24.

15) Robertson SA, Mau VJ, Young IG, Matthaei KI: Uterine eosinophils and reproductive performance in interleukin 5-deficient mice. J Reprod Fertil 2000; 120:423-432.

16) Gouon-Evans V, Pollard JW: Eotaxin is required for eosinophil homing into the stroma of the pubertal and cycling uterus. Endocrinology 2001; 142:4515-4521.

17) Ain R, Tash JS, Soares MJ: A simple method for the in situ detection of eosinophils. J Immunol Methods 2002; 260:273-278.

18) Schindelin J, Arganda-Carreras I, Frise E, Kaynig V, Longair M, Pietzsch T, Preibisch S, Rueden C, Saalfeld S, Schmid B, Tinevez J-Y, White DJ, et al: Fiji: an open-source platform for biological-image analysis. Nat Methods 2012; 9:676-682.

19) Rueden CT, Schindelin J, Hiner MC, DeZonia BE, Walter AE, Arena ET, Eliceiri KW: ImageJ2: ImageJ for the next generation of scientific image data. BMC Bioinformatics 2017; 18:529.

20) Gleich GJ, Adolphson CR, Leiferman KM: The biology of the eosinophilic leukocyte. Annu Rev Med 1993; 44:85-101.

21) Song Z-H, Li Z-Y, Li D-D, Fang W-N, Liu H-Y, Yang D-D, Meng $\mathrm{C}-\mathrm{Y}$, Yang Y, Peng J-P: Seminal plasma induces inflammation in the uterus through the $\gamma \delta \mathrm{T} / \mathrm{IL}-17$ pathway. Sci Rep 2016; $\mathbf{6 : 2 5 1 1 8 .}$

22) DE FEO VJ: Temporal aspect of uterine sensitivity in the pseudopregnant or pregnant rat. Endocrinology 1963; 72:305-316.

23) Yoshinaga K: Uterine receptivity for blastocyst implantation. Ann N Y Acad Sci 1988; 541:424-431.

24) Wang H, Dey SK: Roadmap to embryo implantation: clues from mouse models. Nat Rev Genet 2006; 7:185-199.

25) Hapangama DK, Kamal AM, Bulmer JN: Estrogen receptor $\beta$ : the guardian of the endometrium. Hum Reprod Update 2015; 21:174193.

26) Lubahn DB, Moyer JS, Golding TS, Couse JF, Korach KS, Smithies O: Alteration of reproductive function but not prenatal sexual development after insertional disruption of the mouse estrogen receptor gene. Proc Natl Acad Sci U S A 1993; 90:11162-11166.

27) Weihua Z, Saji S, Mäkinen S, Cheng G, Jensen E V., Warner M, Gustafsson JA: Estrogen receptor (ER) beta, a modulator of ERalpha in the uterus. Proc Natl Acad Sci U S A 2000; 97:5936-5941.

28) Lee YH, Howe RS, Sha SJ, Teuscher C, Sheehan DM, Lyttle CR: Estrogen regulation of an eosinophil chemotactic factor in the immature rat uterus. Endocrinology 1989; 125:3022-3028

29) Tamaki M, Konno Y, Kobayashi Y, Takeda M, Itoga M, Moritoki Y, Oyamada H, Kayaba H, Chihara J, Ueki S: Expression and functional roles of G-protein-coupled estrogen receptor (GPER) in human eosinophils. Immunol Lett 2014; 160:72-78.

30) Phiel KL, Henderson RA, Adelman SJ, Elloso MM: Differential estrogen receptor gene expression in human peripheral blood mononuclear cell populations. Immunol Lett 2005; 97:107-113.

31) Sánchez-Aguilera A, Méndez-Ferrer S: Regulation of hematopoietic progenitors by estrogens as a basis for new antileukemic strategies. Mol Cell Oncol 2016; 3:1-3.

32) Tan J, Paria BC, Dey SK, Das SK: Differential uterine expression of estrogen and progesterone receptors correlates with uterine preparation for implantation and decidualization in the mouse. Endocrinology 1999; 140:5310-5321.

33) Riffo-Vasquez Y, Ligeiro de Oliveira AP, Page CP, Spina D, Tavares-de-Lima W: Role of sex hormones in allergic inflammation in mice. Clin Exp Allergy 2007; 37:459-470.

34) Douin-Echinard V, Calippe B, Billon-Gales A, Fontaine C, Lenfant F, Tremollieres F, Bayard F, Guery J-C, Arnal J-F, Gourdy P: Estradiol administration controls eosinophilia through estrogen receptor- activation during acute peritoneal inflammation. J Leukoc Biol 2011; 90:145-154.

35) Dekel N, Gnainsky Y, Granot I, Racicot K, Mor G: The role of inflammation for a successful implantation. Am J Reprod Immunol 2014; 72:141-147.

36) Cha J, Sun X, Dey SK: Mechanisms of implantation: strategies for successful pregnancy. Nat Med 2012; 18:1754-1767.

37) Yoshinaga K: Review of factors essential for blastocyst implantation for their modulating effects on the maternal immune system. Semin Cell Dev Biol 2008; 19:161-169. 